\title{
Book Review: Understanding the Effects of Immediate Electronic Corrective Feedback on Second Language Development
}

\author{
Tiefu Zhang * \\ School of Foreign Languages, University of Electronic Science and Technology of China, Chengdu, China
}

Keywords: computer-mediated (CM), corrective feedback, computer-assisted language learning (CALL), second language acquisition (SLA), learner attitudes/perceptions, English as a foreign language

\begin{abstract}
A Book Review on
Understanding the Effects of Immediate Electronic Corrective Feedback on Second Language Development
\end{abstract}

Jean Marguerite Jimenez (Bern: Peter Lang), 2020, 252 pages, ISBN: 9783034338158

\section{OPEN ACCESS}

Edited and reviewed by: Ting-Chia Hsu,

National Taiwan Normal

University, Taiwan

*Correspondence:

Tiefu Zhang

tiefu@uestc.edu.cn

Specialty section:

This article was submitted to

Educational Psychology,

a section of the journal

Frontiers in Education

Received: 07 July 2020 Accepted: 26 October 2020 Published: 17 November 2020

Citation:

Zhang T (2020) Book Review:

Understanding the Effects of Immediate Electronic Corrective Feedback on Second Language

Development. Front. Educ. 5:580816. doi: 10.3389/feduc.2020.580816
Corrective feedback is an important pedagogical tool to accomplish teaching and learning in second language classrooms. Parallel to the inquiry into oral and written corrective feedback in both classroom and laboratory settings, researchers in the field of second language acquisition (SLA) have examined the effectiveness of corrective feedback in computer-assisted language learning (CALL). The book "Understanding the Effects of Immediate Electronic Corrective Feedback on Second Language Development," written by Jean M. Jimenez (Jimenez, 2020) is a timely contribution to the continuing discussion of whether and how corrective feedback facilitates second language development in CALL environments. Based on the author's Ph.D. thesis submitted to Lancaster University in 2018, this volume has a precise focus on immediate electronic corrective feedback, organized into six chapters.

The book opens with an introductory section in which the author describes the motivation to conduct the research project within an Italian English as foreign language (EFL) context. The research aims are then clearly stated, namely, to examine "the extent which immediate electronic corrective feedback given to EFL students carrying out CALL activities can affect second language development," to understand "whether learners processing of feedback differs depending on the type of feedback and the type of activity," and to gain "insight into learners' preferences and attitudes toward corrective feedback" (p. 22). The second section of this chapter is an overview of different types of corrective feedback provided in oral, written, and computer-mediated contexts, with a focus on distinguishing between explicit and implicit feedback types in CALL. The chapter ends with explaining the structure of the volume.

Chapter 2 marshals the literature pertinent to the role of corrective feedback in second language development which supports the potential contribution of immediate electronic corrective feedback. Through this chapter, the author attempts to convince that CALL can be a fruitful environment in which corrective feedback can be provided in an individualized and consistent way and, in turn, studies in this domain can inform SLA research as well as pedagogical practices. The chapter begins by reviewing the theoretical basis for corrective feedback. In introducing the theoretical framework for her research, which is firmly grounded in cognitive theories of SLA (e.g., the Noticing Hypothesis and the Skill Acquisition Theory), the author informs the reader that SLA theories differ as to whether corrective feedback plays a facilitative role. 
The chapter then critically discusses the findings based on meta-analyses of corrective feedback in general, and previous studies into corrective feedback in CALL in particular. As well as helping the reader gain an overview of research gaps, the merits of investigating corrective feedback in CALL with Italian EFL learners are demonstrated, particularly concerning the feedback type (explicit vs. implicit) and the CALL activity type (fill-inblanks vs. multiple choice). In addition to reviewing research on the effectiveness of corrective feedback on the acquisition of the simple past tense in English and learners' attitudes toward corrective feedback, this chapter further identifies several underexplored research areas regarding the linguistic type and learner preferences.

Chapter 3 presents the methodological framework to address the five research questions raised in the first two chapters. Written in a rigorous style, this chapter first presents an overview of the study, providing a detailed justification for the choice of experimental design. It then describes the particular context and the participants being studied, including an explanation of the high attrition rate in the sample size. The author also provides a rationale for targeting both regular and irregular past tense forms. Readers who are interested in CALL pedagogical tools, for example, immediate electronic corrective feedback types and activities, will find the methods discussed in Chapter 3 exceedingly useful, as many researchers have had difficulty designing electronic feedback conditions and assessing learning outcomes with appropriate measures. To end the chapter, the author discusses how questionnaire data on learners' preferences for receiving corrective feedback can supplement the quantitative results.

Chapter 4 reports the results of the first four research questions, which are based on the same data set, an analysis of three outcome measures (i.e., guided writing task, grammaticality judgment task, and unbanked gap filling task), and are interrelated. A feature of this chapter is that, at the outset, by illustrating the results of preliminary analysis, the author carefully explains why and how particular parametric tests (e.g., ANCOVA) are employed and to what extent the outcome measures employed can be reliable and valid. Despite the complexity of the experimental design, this chapter is well-presented with clear tables and figures that make the description of the results easy to follow. The author convincingly demonstrates a facilitative role of immediate electronic corrective feedback for L2 development and a long-term benefit of fillin-the-blanks activities. However, there is no evidence that one feedback is superior over the other, nor an interaction between the feedback type and activity type.

Since the fifth research question stands alone, the pertinent results are presented separately in Chapter 5 . While restating the questionnaire data collection and analysis procedures, the author reiterates the importance of addressing learners' preferences for corrective feedback. The results of the descriptive statistics of close-ended items and content analysis of open-ended items are organized according to the group condition. The findings, as the author concludes, reveal a positive attitude toward the provision of feedback and a mixed preference for feedback types among students.
Chapter 6 is divided into two parts. The first part interrogates the main findings within the theoretical framework established in Chapter 2 and compares them with previous studies in the same domain. What may catch the reader's eye is that the author provides an insightful interpretation of some nonsignificant patterns observed in the study. For example, the author articulates why the explicit feedback in her study is equally effective as the implicit feedback. Results from the exit questionnaire lead to a rich discussion on learners' preferences for electronic corrective feedback and perceptions of its usefulness and ease of use, which in turn helps the author interpret the experimental results adequately and enrich her discussion of theoretical and pedagogical implications in the second part.

This book will appeal to both second and foreign language researchers considering corrective feedback studies, CALL teachers, teacher educators, and material developers. It succeeds in identifying the importance of corrective feedback being timely, prompted, and consistent (Li and Vuono, 2019) to set in motion the stages of cognitive processing of it. One of the strengths of the book lies in the author's clear decision about, and adequate choice of, the relevant literature. She has anchored the research in its proper educational, social and research context, in this case an Italian EFL context. This is typically reflected in the organization of Chapter 2 which is appropriately planned and presented. The reader will be impressed by the way the author synthesizes the research literature and documents empirical studies using a visually attractive table (p. 54-63). Another strength of the book is its clear, systematic and consistent description of the intervention and data collection and analysis procedures, which ensure that the study is well-grounded in the research traditions with which the author is familiar. The methodology chapter will greatly benefit the reader, especially Ph.D. researchers and teachers who are enthusiastic about integrating computermediated technology into classrooms. It not only provides a toolkit for conducting and strengthening the validity of research on corrective feedback but also shows approaches to investigating key issues from a learner's perspective.

Like many other volumes edited and revised from doctoral dissertations, this book reflects its origins as a Ph.D. thesismost notably in the presentation of the research questions, which appear repetitively in almost all chapters. Similarly, when reading the discussion chapter, the reader may notice some repetitive statements from earlier chapters. Another weakness of the book is that the review of the literature appears less up-to-date. For example, research articles on the effects of corrective feedback cited in Chapters 1 and 2 are published mostly between 2000 and 2017. What it suggests is that the book would have benefited from including more recently published studies investigating corrective feedback in computer-mediated communication contexts (e.g., Yamashita, 2019).

Overall, this volume provides a comprehensive and systematic examination of preprogrammed computer delivered corrective feedback on second language development associated with several crucial factors. It offers a methodological model of how to conduct experimental research within the cognitive perspective of SLA and, particularly, insights into the importance 
of understanding the learning effects of corrective feedback from the learner perspective. Given its topical and thought-provoking content, Jimenez's book is a must-read for anyone interested in corrective feedback in traditional classrooms in general and CALL classrooms in particular.

\section{AUTHOR CONTRIBUTIONS}

The author confirms being the sole contributor of this work and has approved it for publication.

\section{REFERENCES}

Jimenez, J. M. (2020). Understanding the Effects of Immediate Electronic Corrective Feedback on Second Language Development. Berlin: Peter Lang Gmbh, Internationaler Verlag Der Wissenschaften.

Li, S., and Vuono, A. (2019). Twenty-five years of research on oral and written corrective feedback in system. System 84, 93-109. doi: $10.1016 /$ j.system.2019.05.006

Yamashita, T. (2019). The comparative effects of metalinguistic clue and metalinguistic explanation in computer-mediated form-focused practice: does prior knowledge matter? Comput. Assist. Lang. Learn. 32, 98-117. doi: $10.1080 / 09588221.2018 .1488736$

\section{FUNDING}

This review was supported by a grant from University of Electronic Science and Technology of China (No. Y030202059018034) and Sichuan Provincial Project for Higher Education Teaching Reform (No. JG2018-215).

\section{ACKNOWLEDGMENTS}

I would like to thank the editor and the reviewer for their valuable comments on the book review.

Conflict of Interest: The author declares that the research was conducted in the absence of any commercial or financial relationships that could be construed as a potential conflict of interest.

Copyright (c) 2020 Zhang. This is an open-access article distributed under the terms of the Creative Commons Attribution License (CC BY). The use, distribution or reproduction in other forums is permitted, provided the original author(s) and the copyright owner(s) are credited and that the original publication in this journal is cited, in accordance with accepted academic practice. No use, distribution or reproduction is permitted which does not comply with these terms. 